\title{
Teorías en diálogo: representaciones sociales y memoria colectiva
}

\section{Theories in dialogue: Social representations and collective memory}

\author{
Martha de Alba González* \\ Departamento de Sociología, Universidad Autónoma Metropolitana-Iztapalapa, \\ Ciudad de México, México \\ DoI: http://dx.doi.org/10.28928/revistaiztapalapa/802016/aot1/dealbagonzalezm
}

\begin{abstract}
Resumen
Los conceptos de representaciones sociales y memoria colectiva tienen un estrecho vínculo debido a que toman su origen en el pensamiento de Durkheim. El presente artículo tiene como propósito esclarecer las relaciones entre ellos. En un primer momento, nos remitimos al contexto sociohistórico en el que Moscovici y Halbawachs desarrollan la teoría de las representaciones sociales y de la memoria colectiva, y su nexo con la sociología durkheimiana. Posteriormente, se realiza una síntesis de ambos conceptos, para establecer puentes entre ellos. Finalmente, se reflexiona sobre su pertinencia y viabilidad para el estudio del pensamiento social contemporáneo.
\end{abstract}

Palabras clave: representaciones colectivas, memoria social, metodología, Durkheim, pensamiento social

\begin{abstract}
The concepts of social representations and collective memory are related because both are inspired on Durkheim's ideas. This article intends to clarify the relationship between them. First, we trace the socio-historic context where Moscovici and Halbwachs developed their theories, in the frame of Durkheim's sociology. Afterwards, we present both concepts and possible links between them. Finally, we make a discussion about their application to the study of contemporary social thinking.
\end{abstract}

Keywords: social representation, collective memory, methodology, Durkheim, social thinking.

I La autora agradece a los evaluadores sus valiosas sugerencias para mejorar la versión precedente de este artículo, el cual fue elaborado a partir de la conferencia "Representaciones sociales y Memoria colectiva: una re-lectura" presentada en VII Jorna-

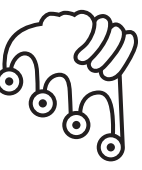

IZTAPALAPA

Agua sobre lajas

Doctora en Psicología Social por la Escuela de Altos Estudios en Ciencias Sociales, en Francia, con una especialidad en psicología ambiental por la Universidad René Descartes, París V. mdealba.uami@gmail.com 
E 1 objetivo de este texto es reconstruir un diálogo entre los conceptos de representaciones sociales (Rs) y de la memoria colectiva (MC). Esta meta resulta de dos motivaciones principales. La primera es que en el campo de las representaciones sociales, la teoría de la memoria colectiva es el principal referente para abordar el fenómeno de la memoria desde una perspectiva social, por lo que es necesario reflexionar sobre las similitudes y diferencias entre ambos constructos teóricos. La segunda corresponde a un interés pedagógico: una vez esclarecidos los conceptos, cabe preguntarse cómo crear puentes entre ellos y qué tipo de metodologías serían pertinentes para analizarlos.

Este diálogo se desarrolla en varias etapas. Inicia con la recuperación de las raíces de la sociología de Durkheim en el desarrollo de los conceptos de MC y Rs. Sigue con una exposición sintética de la TRS propuesta por Moscovici (1961/1976) y del concepto de la MC de Halbwachs (1925, I950), que contribuirá al establecimiento de diferencias y puntos comunes entre las dos propuestas teóricas. El diálogo cierra con una serie de reflexiones sobre la pertinencia de su desarrollo para abordar el creciente interés por la memoria social, en relación con las representaciones sociales del presente.

\section{Durkheim, Halbwachs y Moscovici}

$\mathrm{Al}$ revisar los estudios sobre representaciones sociales de hechos pasados, pareciera existir una relación natural e incuestionable entre la TRS y el concepto de memoria colectiva de Halbwachs (1925; 1950). El lazo entre las representaciones sociales y la memoria colectiva es estrecho porque comparten una fuente epistemológica común, que es la sociología durkheimiana, particularmente en lo que se refiere a la noción de representaciones colectivas.

das Internacionales de Representaciones Sociales. 50 años: Memorias, desafíos contemporáneos y perspectivas, en Vitória, Brasil, en 2011. 
Una mirada cuidadosa hacia estos conceptos conduce inevitablemente a reflexionar sobre algunas preguntas que hacen menos obvia la similitud entre ellos, o que al menos alertan sobre la pertinencia de relacionarlos. Enuncio algunas dudas que no solo me surgieron a mí, sino también a diversos autores que tratan el tema:

- ¿Cuál es la actualidad de la teoría de la memoria colectiva, desarrollada por Halbwachs (entre 1925 y 1944) en un contexto sociohistórico diferente al nuestro? - ¿Cuál es la diferencia entre memoria individual, colectiva y social?

- ¿Cuál es el estatuto ontológico del concepto de memoria colectiva o social?, es decir: ¿podemos suponer que existe una suerte de conciencia colectiva autónoma e independiente de los miembros de la sociedad?

- ¿La memoria colectiva es una representación social?, de ser el caso, ¿̇usaremos los mismos principios y métodos para estudiarla?

- ¿Cuál es el papel del individuo en el marco de estas teorías?, ¿"autómata social” o individuo autónomo?

Más que intentar responder definitivamente a estas preguntas difíciles, prefiero pensar este artículo como una reflexión abierta. Sugiero comenzar el análisis de la relación entre la TRS y la TMC situando a cada autor en su contexto. ¿En qué momento y en relación a qué discusión teórica surgieron ambas? El esquema I intenta resumir las trayectorias de pensamiento que siguieron Halbwachs y Moscovici para desarrollar sus teorías, a partir de la influencia de las ideas de Durkheim.

Si bien es cierto que tanto Halbwachs como Moscovici reconocen la influencia de Durkheim, ambos reformulan las ideas de este por al menos dos razones. La primera es que cada uno adapta las nociones de la sociología durkheimiana para tratar de comprender el contexto sociohistórico en que están insertos, ante el cual tienen una mirada crítica. Halbwachs se formó en el ambiente de las modernas ciudades industrializadas de principios del siglo xx. Dejó su teoría de la memoria colectiva inconclusa al fallecer en el campo de concentración de Buchenwald, en 1944. Moscovici propone su TRS en un contexto distinto: en el marco de la modernidad consumista, caracterizada por el rápido desarrollo de los medios de comunicación de masas, la tecnologización de la vida cotidiana, el trastrocamiento de valores durante los años sesenta, por solo mencionar algunos aspectos.

La segunda razón es que ambos autores hacen una lectura de Durkheim a la luz de un "diálogo" con otros pensadores. Halbwachs elabora su teoría sobre la memoria colectiva con base en una fuerte crítica a las ideas de Bergson, y la hace evolucionar para dar respuesta a los comentarios críticos de Marc Bloch al planteamiento de los marcos sociales; incorpora en su sociología ideas de Leibniz y las experiencias 


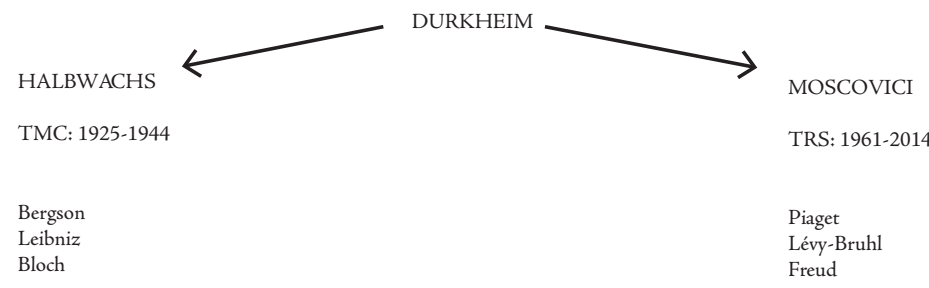

Contexto: entre la Primera y la Segunda Guerra Mundial Modernidad industrial - consumista

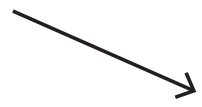

Contexto después de la Segunda Guerra Mundial Modernidad consumista - Posmodernidad

Relación individuo-sociedad

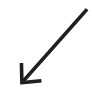

La sociogénesis del pensamiento social

Representaciones sociales como formas de entender el mundo

Memoria como una construcción social del pasado en el presente

Esquema 1. Influencia de Durkheim en las teorías de la memoria colectiva y las representaciones sociales

provenientes de su contacto con la Escuela de Chicago. Por su parte, Moscovici (1989) reelabora el concepto original de las representaciones colectivas de Durkheim, retomando a autores como Piaget, Lévy-Bruhl y Freud, en el contexto de la psicología social posterior a los años cincuenta.

A pesar de sus recorridos teóricos particulares, Moscovici y Halbwachs comparten el interés por entender el pensamiento social, así como la postura en cuanto a la sociogénesis de la memoria y de las representaciones.

El peso del contexto en el que están viviendo no es menor en el desarrollo de sus teorías. Ambos autores hablan de las transformaciones que están presenciando y que requieren marcos de comprensión distintos a los de las sociedades tradicionales observadas por Durkheim. Una mayor rapidez de los cambios sociales, un mayor peso del individuo en la sociedad moderna y una mayor movilidad social otorgan mayor visibilidad al individuo como un sujeto más activo socialmente y al grupo como un agente dinámico, cambiante y promotor del cambio social, como en el caso de las minorías activas observadas por Moscovici (1961/1976).

En su artículo sobre las representaciones individuales (RI) y las representaciones colectivas (RC) de 1898, Durkheim hizo una división tajante entre estos procesos, asignándolos como objeto de estudio de la psicología el primero y de la sociología el 
segundo, dejando a una disciplina intermedia, una suerte de sociología psicológica, la tarea de analizar la interfaz entre el individuo y la sociedad (Durkheim, 1895/1986).

Moscovici y Halbwachs parecen adoptar la propuesta, al situar su análisis de las representaciones y de la memoria en el individuo para fundamentar el peso de la sociedad y de la cultura en tales procesos. Reconocen el papel de los intercambios entre los miembros de los grupos y entre las colectividades que componen sociedades enteras. Sus teorías dan cuenta de lo social en el individuo y del papel del individuo en la sociedad. El esquema 2 intenta resumir la manera en que los tres autores concibieron sus conceptos a partir de las relaciones que los individuos mantienen con la sociedad. El individualismo y la movilidad social creciente en las sociedades modernas, así como sus acelerados cambios sociales, dieron mayor peso al individuo como actores sociales del cambio y como creadores de pensamiento social. Esquema 2. De los hechos sociales a los sujetos sociales

\begin{tabular}{|c|c|c|c|c|}
\hline & & Durkheim & Moscovici & Halbwachs \\
\hline & Individuos & $\begin{array}{l}\text { Representaciones } \\
\text { individuales: proceso } \\
\text { psíquico, objeto de estudio } \\
\text { de la psicología }\end{array}$ & $\begin{array}{l}\text { Representaciones sociales: } \\
\text { formas de conocimiento de } \\
\text { sentido común elaboradas } \\
\text { por sujetos sociales, }\end{array}$ & $\begin{array}{l}\text { Memoria colectiva/social: } \\
\text { memoria (individual, } \\
\text { grupal y social) construida } \\
\text { a partir de marcos sociales }\end{array}$ \\
\hline v & Interacción & $\begin{array}{l}\text { Psicología sociológica: } \\
\text { interfase entre RI y RC }\end{array}$ & $\begin{array}{l}\text { pensamiento social } \\
\text { dinámico y flexible, } \\
\text { socialización de la ciencia, }\end{array}$ & $\begin{array}{l}\text { sociales como sistemas de } \\
\text { representaciones propias a } \\
\text { la sociedad y a los grupos, }\end{array}$ \\
\hline & Sociedades & $\begin{array}{l}\text { Representaciones colectivas: } \\
\text { hechos sociales, } \\
\text { preexistentes, coercitivos e } \\
\text { inmutables, objeto de } \\
\text { estudio de la sociología. } \\
\text { Sociedades tradicionales }\end{array}$ & $\begin{array}{l}\text { comunicación social, mirada } \\
\text { pluridisciplianria. } \\
\text { Sociedades modernas, } \\
\text { masivas y tecnologizadas }\end{array}$ & $\begin{array}{l}\text { simbólica, grupos como } \\
\text { socializadores, memoria } \\
\text { dinámica, flexible y } \\
\text { múltiple. } \\
\text { Sociedades modernas }\end{array}$ \\
\hline
\end{tabular}

Rapidez en los cambios sociales en sociedades modernas

\section{Las representaciones sociales}

En el campo de la psicología social existen pocas teorías que permitan estudiar fenómenos sociales de forma compleja y holística, enfocadas a comprender formas de pensar, actuar y sentir, interpretadas en el contexto histórico, social y cultural en donde se producen. En la disciplina, la TRs puede considerarse más una epistemología que una teoría, en la medida en que no solo ofrece una posible explicación de la forma en que se manifiestan y operan el pensamiento y la acción social, sino que también lleva implícita una visión del ser humano y una heurística para su estudio. 
La teoría establece que el ser humano construye Rs para comprender su mundo y actuar en él. Tales representaciones se construyen a partir de otras que ha ido adquiriendo a lo largo de su vida, a través de la educación formal y familiar, de valores, creencias, mitos y leyendas. El mundo simbólico de una sociedad fue estudiado por Durkheim bajo la forma de representaciones colectivas, vistas como hechos sociales que se imponen a sus miembros, por medio de la fuerza de las instituciones.

Bajo la influencia de la teoría piagetiana del desarrollo del pensamiento y de la propuesta de Lévy-Brhul sobre el paso del pensamiento primitivo al pensamiento civilizado, Moscovici, reformula el concepto de RC para colocarlo en el campo de la psicología social, a fin de comprender la forma en que las personas de mediados del siglo $\mathrm{xx}$, con valores modernos, acceso a la tecnología y a la información, elaboran un sentido común con el que se comunican y con el que afrontan su vida cotidiana.

La "modernización" del concepto de RC de Durkheim implicó un cambio de unidad de análisis. Pasaron de estudiarse como hechos sociales inmutables y coercitivos a nivel de las instituciones y de los colectivos, a considerarse como fenómenos psicosociales presentes en individuos sociales. Aunque fuertemente determinados por sus grupos de pertenencia, la sociedad y la cultura en su conjunto, las personas son capaces de crear sus propias de representaciones de manera flexible y creativa, a fin de lidiar con un mundo activo, dinámico, cambiante, masivo y veloz. La intensidad de la comunicación directa e indirecta (medios electrónicos) lleva a los sujetos a construir RS con rapidez y eficacia. En el mundo contemporáneo nos vemos obligados a tratar de comprender qué son los alimentos genéticamente modificados, el genoma humano, los tsunamis, las guerras en países lejanos, el espionaje vía wikileaks, etc. En el ámbito local, todo ello coexiste con los temas de interés en la esfera púbica nacional que se nos presenta en los medios, a los que tratamos de dar sentido a través de las múltiples explicaciones de sentido común en las que mezclamos teorías ingenuas sobre política, economía y cultura de la corrupción. Nos asustan las tasas de desempleo, la pobreza y la inseguridad, al mismo tiempo que nos entretenemos con el consumo cultural. Esta complejidad fenomenológica no sería posible sin el artificio de un constante trabajo de construcción de representaciones para guiarnos en el mundo en el que vivimos cotidianamente. Representaciones que son sociales porque nos fueron heredadas, porque son compartidas con otros y porque las comunicamos frecuentemente en la interacción social.

La TRS establece que la construcción de tales Rs se encuentra mediada por el sistema normativo y de valores sociales. Generar una opinión o una explicación sobre un tema dependerá de lo que nos permitamos expresar en función de las normas y valores del medio social en el que estamos insertos, núcleo básico de nuestras inte- 
racciones y comunicación con otros. De esta forma, el creacionismo tiene lugar en el ámbito de la religión católica y cristiana, aunque será difícil sostenerlo en el de la ciencia. Temas sensibles, como la sexualidad, se expresarán con palabras veladas en un contexto donde no está permitido llamar a los órganos sexuales por su nombre. Las posiciones políticas, racistas o discriminatorias también pasarán por la censura social de quien nos escuche.

A nivel sociocognitivo, las Rs operan por medio de dos procesos complementarios: la objetivación y el anclaje. El primero consiste en materializar una idea abstracta en un esquema concreto, mediante el lenguaje, una figura, un símbolo (la cruz, la trinidad, como símbolos del catolicismo, por ejemplo). El segundo refiere al nexo que establecemos con nuestro conocimiento pasado para interpretar el presente, aquello que es nuevo y desconocido. Activamos categorías preexistentes para nombrar y clasificar los eventos del entorno, para hacerlos familiares y manejables. Una sesión terapéutica de psicoanálisis podría asimilarse a la confesión católica, más arcaica y tradicional, con el fin de entender ese proceso íntimo de comunicación personal. La historia y la memoria colectiva o social, la construcción sociocultural del recuerdo, constituyen fuentes de anclaje de las representaciones sociales elaboradas en el presente.

Después de esta somera exposición, podemos concluir que la visión del ser humano que ofrece la TRs puede representarse en una relación tríadica, que Moscovici (1982) representa de la siguiente forma: objeto-alter-ego. El ego, el individuo, se relaciona con el objeto (el mundo) a través de la alteridad (la sociedad representada por otro individuo, un conjunto de personas, las instituciones, los grupos culturales o la nación).

\section{Metodología: sujeto/objeto de representación}

La TRS recomienda no estudiar las RS de forma abstracta, sin que haya sujetos $u$ objetos de representación definidos. El procedimiento metodológico consistiría en identificar el sujeto, individual o social, que construye la representación de un objeto socialmente pertinente. Es decir, las representaciones sociales son de alguien y de algo. El alguien puede ser un actor social específico o un grupo. Podemos estudiar, por ejemplo, las representaciones sociales de la vejez en el discurso del secretario de Salud, o en los programas de gobierno de una institución determinada. La representación de la ciudad en grupos de residentes, en funcionarios de medio ambiente, en asociaciones de la sociedad civil, etcétera. 
Los métodos corresponden a las distintas formas de observación de manifestaciones del pensamiento o de la acción: discursos (entrevistas, cuestionarios, documentos, comunicación directa, etc.), imágenes, rituales, prácticas, performances, etc. La gama metodológica se ubica entre lo cualitativo y lo cuantitativo, dependiendo de los objetivos particulares del investigador. En algunos estudios es recurrente encontrar la triangulación metodológica, es decir, la combinación de métodos y estrategias de análisis para observar las RS desde distintos aspectos y herramientas.

Las diferentes perspectivas teóricas desarrolladas en el campo de las Rs por los discípulos de Moscovici se distinguen por el uso de diversas metodologías. La estructural empleará un método específico para encontrar los elementos periféricos y centrales de una representación (Flament, 1989; Abric, 1994). Otra buscará los sistemas normativos que rigen la construcción de representaciones (Doise, 1989). La visión antropológica de las Rs empleará métodos propios de la investigación cualitativa: entrevista a profundidad, etnografía, análisis de documentación, etc. (Jodelet, 1989). El enfoque dialógico buscará las Rs en el análisis de los discursos (Markova, 200I).

Existe cierta libertad metodológica en el empleo de técnicas para observar las representaciones sociales de una amplia gama de fenómenos convertidos en objetos de estudio, en contextos sociales diversos.

Las representaciones sociales pueden ser estudiadas de acuerdo con varios niveles de análisis (Doise, 1982). En la línea individual las encontramos en el pensamiento o las narrativas de una persona; por ejemplo, podemos estudiar las representaciones sociales de la mujer o de las relaciones de género en la obra de Virginia Wolf. En las relaciones interpersonales las distinguimos bajo la forma de diálogos, conversaciones, intercambios escritos, prácticas de interacción, etc. Podemos también estudiar las representaciones sociales que comparten ciertos grupos sobre un tema social específico; por ejemplo, las representaciones sociales de productos transgénicos en grupos ecologistas. Las instituciones y sus representantes construyen y transmiten representaciones sociales sobre los temas que las ocupan. Los ideales nacionales, las grandes ideologías o los sistemas simbólicos que rigen el mundo global han sido abordados a partir de la TRs.

Como se verá a continuación, la teoría de la memoria colectiva permite retomar estos mismos niveles de unidad de análisis. 


\section{La memoria colectiva}

En este apartado se expondrá la noción de memoria colectiva mediante un esquema sintético (véase esquema 3), elaborado a partir de la revisión de los marcos sociales de la memoria (Halbwachs, 1925/1994) y del libro póstumo de La memoria colectiva (1950/1997).

Se ha criticado a Halbwachs por un acentuado sociologismo, al proponer la memoria como un fenómeno colectivo. Sin embargo, tanto los Marcos Sociales como la memoria colectiva nos presentan una fenomenología del recuerdo a partir de la cual Halbwachs lleva al lector de la experiencia individual al plano del grupo y de la sociedad. La experiencia individual no es negada, sino que, desde su perspectiva, ocupa un lugar menor en la vida eminentemente social del sujeto.

Se puede concebir la teoría de la memoria colectiva como una combinación de círculos o medios sociales en los que se encuentra el individuo. La esfera más general simboliza a la cultura, al lenguaje, al tiempo y al espacio como marcos sociales básicos que orientan la experiencia del sujeto y sus formas de ver el mundo. Estos marcos sociales generales otorgan las categorías primarias de pensamiento compartidas por una sociedad. El pensamiento, la memoria, la experiencia, se expresan por medio de un lenguaje social y culturalmente definido, son procesos estructurados por las nociones socialmente construidas de tiempo y espacio.

\section{CULTURA}

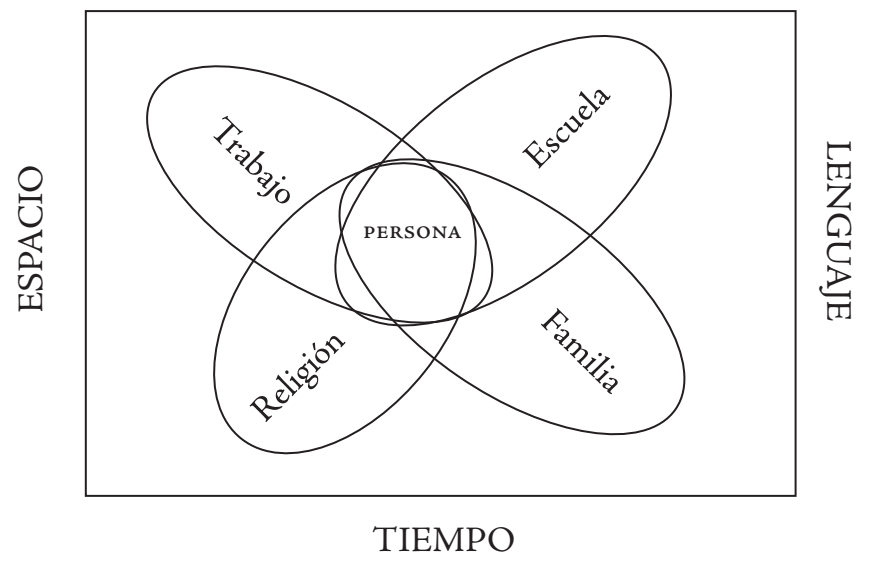

Esquema 3. Teoría de la memoria colectiva de Halbwachs 
El tiempo social es el tiempo de la experiencia cotidiana, que nos lleva a cumplir con una regulación de nuestras actividades en función de los otros. Es el tiempo de los calendarios cívicos y religiosos, pero también el de una biología social que regula las funciones vitales desde marcos sociales diversos.

El espacio es más que el contexto material que nos rodea, es un conjunto de símbolos que cobran significado a partir de haber dejado la huella de nuestras experiencias en él, como individuos o como colectivo. Proyecta la imagen del grupo, se incorpora en su identidad y en sus recuerdos.

La relación que el individuo mantiene con estos grandes marcos sociales se encuentra mediada por los grupos a los que pertenece, esencialmente la familia. Los grupos definen también sus tiempos, sus espacios, crean sus costumbres y tienen ciertas formas de lenguaje. Halbwachs resalta aquellos grupos que ocupan un papel importante en la socialización del sujeto: los colectivos profesionales, educativos, religiosos y, como ya mencionamos, la familia. El intercambio de experiencias, de memorias y de nociones entre los grupos hace que estos cambien a la par que sus miembros.

Existe cierta controversia en cuanto a la diferencia entre memoria colectiva y memoria social. Para algunos autores, Halbwachs es confuso al respecto. Para otros, la memoria colectiva corresponde a los grupos, mientras que la memoria social hace referencia al vasto entramado de construcciones simbólicas que produce la sociedad entera.

Otro aspecto controversial de la teoría de la memoria colectiva es el postulado de que existe una memoria social autónoma a los individuos que la crean. Frédéric Le Paumier y Marisa Zavalloni (2002), como otros autores, cuestionan la idea de que la colectividad posea una conciencia que funcione como una memoria. Ellos mismos proponen una solución, haciendo una lectura de Halbwachs que coloca la memoria colectiva en los individuos y en las interacciones sociales: "habrá que comprender que las dinámicas de memoria se ponen en juego entre los individuos, los grupos a los que pertenecen o no, y la sociedad, a través de situaciones espaciales y temporales, así como a través del lenguaje, sabiendo que únicamente los individuos poseen la facultad de recordar" (Le Paumier y Zavalloni 2002:66).

Cuando Halbwachs postula que el recuerdo se crea en los marcos sociales, se refiere al hecho de que estos constituyen las herramientas que servirán al sujeto no solo para construir recuerdos, sino toda forma de ver y organizar el mundo. Vemos aquí la influencia de Durkheim: el grupo, la cultura, proporciona a sus miembros las categorías elementales de pensamiento (Durkheim, I912). 
Este postulado es similar al de la construcción de las representaciones sociales: son formas de pensamiento socialmente elaboradas, ancladas en un cuerpo de conocimiento preexistente que se va modificando con la incorporación de nuevos conocimientos o experiencias.

El recuerdo se crea en la interacción, real o simbólica, del sujeto con el grupo. De manera similar a la forma de operación del pensamiento natural que plantea Moscovici (I96I), la memoria tiene su propia lógica para dar cuerpo (podríamos decir objetivar) a recuerdos que den sentido a la situación del sujeto en el presente. La memoria es un acto inteligente de sentido y de coherencia entre sentimientos y pensamientos del pasado y los del presente.

\section{Semejanzas y diferencias entre las representaciones sociales y la memoria colectiva}

Los presupuestos teóricos compartidos por las teorías de la memoria colectiva y de las representaciones sociales quedan resumidos en los siguientes puntos. Tanto Halbwachs como Moscovici postulan:

- Una construcción social de la realidad presente y pasada, que no es una reproducción o copia fiel del objeto o la situación representada o recordada.

- Una sociogénesis del pensamiento social.

- La importancia del papel de los grupos, la sociedad, la cultura y la historia en la construcción de procesos psicológicos.

- El papel de la interacción (real o simbólica) y de la comunicación.

- El dinamismo, la flexibilidad y la multiplicidad como características de la memoria colectiva y de las representaciones sociales.

- El funcionamiento del pensamiento social en forma de esquema: el aspecto figurativo del proceso de objetivación de la Trs y el concepto de "mosaico" o esquema sintético de la memoria colectiva.

- Una relación diálectica entre presente-pasado en la construcción del pensamiento social.

Existen también algunas divergencias entre ambas teorías que nos parecen importantes:

- La TRS no incorpora (explícitamente) el tiempo ni el espacio como categorías básicas o primarias que intervienen en el funcionamiento o en la construcción de las Rs. 
- La тмC no establece vínculo directo con las prácticas sociales. La memoria como directiva de prácticas sociales es mediada por los significados del contexto en el presente.

- La TMC otorga un papel importante a la socialización de los miembros del grupo (familia) en forma explícita.

- La TMC no establece procesos de operación psicosociales del recuerdo, como los procesos de objetivación y anclaje en la Trs.

Estas diferencias entre una y otra teoría no las alejan, sino que permiten su complementariedad, como lo veremos en la revisión del estado del arte sobre la relación entre ambos conceptos. Una revisión de los trabajos que relacionan la memoria social y las Rs permite observar que no todos los autores retoman el concepto de memoria colectiva de Halbwachs. Algunos consideran necesario reconsiderarlo o reformularlo a partir de las propuestas más recientes sobre la memoria social. Sin embargo, la referencia a Halbwachs permanece en ellos como un anclaje inevitable, debido quizá, como lo sugieren Haas y Jodelet (1999), a la heterogeneidad de conceptos distintos que describen la memoria social. Aspecto también señalado por Celso Pereira de Sà (2005).

El primer fruto evidente al relacionar las Rs y la MC es la introducción de la dimensión temporal e histórica en la concepción del pensamiento social, en donde confluyen pasado, presente y futuro en la construcción social de la realidad de forma interdependiente. En el esquema 4 se ve cómo ambas teorías tratan la temporalidad en el pensamiento social, así como la función de la memoria en la construcción de las representaciones sociales, y viceversa, el papel que juegan las representaciones sociales (procesos planteados por diversos especialistas en el tema) en la reconstrucción de la memoria colectiva. Finalmente, veremos cómo las representaciones y la memoria contribuyen a una planificación del futuro.

El papel de la memoria colectiva en la Trs (ver primera columna del Esquema 4): La memoria interviene como conocimiento pasado en el que se anclan las representaciones sociales en el presente. Diversos autores relacionan a la memoria colectiva con los siguientes procesos: anclaje, objetivación, themata, metasistema normativo, creencias mágicas, imaginarios y mitos, núcleo central, historia cultural, nexus, experiencia individual, historia de vida.

La función de la representaciones sociales en la memoria colectiva (ver segunda columna del Esquema 4): la representación social es el proceso psicosocial por el que opera la construcción del recuerdo de un evento u objeto social particular, en coherencia con la situación presente del sujeto que evoca tal recuerdo. La repre- 
sentación social le permite actualizar la identidad social que se va reconstruyendo a lo largo del tiempo, es orientadora de prácticas sociales que aunque tienen una relación con el pasado, se realizan el presente.

Pasado

Función de la MC en las Rs MC

Anclaje

Themata

Metasistema normativo

Creencias mágicas

Imaginario y mitos

Núcleo central

Objetivación

Historia cultural

Nexus

Experiencia individual

Historia de vida
Presente

Función de las Rs en la MC

RS

Proceso que hace posible la construcción del pasado

Identidad social

Prácticas sociales
Futuro

Función de Rs y MC en proyección Planificación del futuro

Visión del futuro en la que ciertos aspectos del pasado caen en el olvido

Memoria como legitimadora de proyectos

Esquema 4. Temporaridad del pensamiento social

La función de la memoria colectiva y las representaciones sociales en la proyección del futuro (véase tercera columna del esquema 4): La representación social aparece en las investigaciones como proceso organizador de la situación presente, en el que la memoria contribuye a planificar el futuro en función de las experiencias del pasado. La memoria social o colectiva se convierte en una evidencia legitimadora de proyectos. Los planes futuros dejan en el olvido aquellos aspectos del pasado que no son coherentes con la situación actual o que resultan conflictivos.

\section{Métodos de estudio de la memoria colectiva desde la perspectiva de las RS}

El esquema 5 pretende sintetizar las formas en que la memoria social y las RS pueden manifestarse y ser observadas, a partir del conjunto de trabajos revisados (Laurens y Roussiau, 2002; Connexions, 2003; Pereira de Sà, 2005; Rosa, Bellelli y Bakhurst, 2000; Haas y Jodelet; 1999; Jodelet, 2012, 2010, 1992, 1993, 1987; Banchs, et al,, 2007; Arruda y de Alba, 2007). La síntesis plantea una complementariedad de las teorías al suponer que podemos utilizar las nociones de anclaje y objetivación para observar los procesos de memoria, de forma similar a como lo hacemos para 
el caso de las Rs. En el esquema planteamos distintas formas de anclaje: en primer lugar, el contexto sociocultural e histórico en el que se sitúan individuos y grupos al momento de construir sus representaciones sociales o sus recuerdos. En segundo lugar, el anclaje se relaciona con las experiencias pasadas y el bagaje de conocimientos que han adquirido diferentes actores sociales, vistos como individuos aislados o en interacción, como grupos o como sociedades enteras.

Retomando la fórmula heurística que propone Moscovici para el estudio de las Rs, podemos preguntarnos ¿quién se representa qué?, de la misma manera que ¿quién recuerda qué?

Las representaciones sociales y la memoria colectiva pueden ser estudiadas en relación con distintos actores o sujetos sociales que construyen activamente visiones del mundo y recuerdos, que se manifiestan por medio de discursos, imágenes, prácticas, emociones, espacios y tiempos. Son expresiones materializadas del pensamiento social presente y pasado, que podemos atribuir al proceso de objetivación.

\begin{tabular}{|c|c|c|c|c|}
\hline \multirow{2}{*}{$\begin{array}{l}\text { Contexto } \\
\text { Anclaje/ } \\
\text { objetivación }\end{array}$} & \multicolumn{3}{|c|}{$\begin{array}{l}\text { Historia política y cultural, posición de los individuos y grupos en la } \\
\text { estructura social (igualdad, jerarquía, diferencia, oposición...) }\end{array}$} & \multirow{2}{*}{$\begin{array}{l}\text { Historia, cultura, } \\
\text { política nacional } \\
\text { Sociedad: sociedad } \\
\text { civil y Estado } \\
\text { institucional }\end{array}$} \\
\hline & $\begin{array}{l}\text { Individuo o actor } \\
\text { social }\end{array}$ & Interacción social & $\begin{array}{l}\text { Grupo: familia, } \\
\text { colectivo, comunidad }\end{array}$ & \\
\hline Discursos & \multicolumn{4}{|c|}{ Expresión oral y escrita manifestada por diversos medios de comunicación (en vivo/archivo) } \\
\hline Imágenes & \multicolumn{4}{|c|}{ Expresiones icónicas (dibujo, arte, fotografía, Tv, cine, documental, internet) } \\
\hline $\begin{array}{l}\text { Experiencias } \\
\text { y prácticas } \\
\text { sociales }\end{array}$ & \multicolumn{4}{|c|}{ Acción individual o colectiva, comportamientos y rituales, acción política } \\
\hline Emociones & \multicolumn{4}{|c|}{ Expresiones afectivas personales o grupales (toma de posición, conflicto, motivos...) } \\
\hline Espacio & \multicolumn{4}{|c|}{$\begin{array}{c}\text { Escenarios de la vida privada y pública, espacio significante, regulado, simbólico, reflejo de la } \\
\text { estructura y vida social }\end{array}$} \\
\hline Tiempo & \multicolumn{4}{|c|}{$\begin{array}{l}\text { Historia personal y colectiva, tiempo socialmente definido, ritmos de vida cotidiana, ciclos de } \\
\text { vida }\end{array}$} \\
\hline
\end{tabular}

Esquema 5. Formas de observación de las RS y de la memoria colectiva

Así, tenemos una matriz conceptual y metodológica que permite ubicar los distintos estudios que han tratado conjuntamente representaciones sociales y la memoria colectiva. Por ejemplo, el de Jodelet y Milgram (1976) sobre los mapas mentales de París podría ubicarse en el encuentro de varios actores y formas de expresión de representaciones y memoria: a nivel individual, cuando analizan los 
mapas mentales como estudios de caso en los que se observa la impronta de la historia y de la estructura social, tanto como del pasado de la persona que realiza el dibujo (tiempo de residencia en un barrio, prácticas de vida cotidiana). Las respuestas verbales del cuestionario y el conjunto de dibujos son analizados también a nivel grupal, lo que permite ver que el nivel socioprofesional y la ubicación geográfica generan diferencias en la construcción de las Rs de París. Este es solo un ejemplo de cómo memoria y representaciones sociales confluyen en la construcción de la imagen de esta ciudad entre una muestra de residentes.

Otros estudios han puesto el acento en las emociones suscitadas por imágenes mediáticas que construyen el recuerdo de un evento dramático y catastrófico, como es el caso de la investigación de Annamaría de Rosa sobre la memoria flash en torno a la destrucción de las Torres gemelas el ir de septiembre de 200 (De Rosa, 2005).

En otro registro tenemos la investigación sobre la conmemoración de los 500 años del descubrimiento de América, realizada en diversos países europeos y latinoamericanos, en donde se hace evidente el manejo mediático y político de la memoria histórica, en contraste con la toma de posición de cierto grupos que reivindican un pasado indígena, como lo señalan Pereira de Sà y Oliveira (2002).

Podríamos continuar dando ejemplos de las investigaciones que se han hecho sobre el tema para ver cómo se ubican en este esquema conceptual que une la TRS con la teoría de la memoria colectiva. Sin embargo, la finalidad de su planteamiento es pedagógica: que pueda servir como una guía de orientación para el diseño de investigaciones futuras que pretendan abordar estos temas. ¿Quiénes son los actores de representaciones y recuerdos colectivos? ¿Cuál es el objeto de representación y de memoria? ¿Cuál es el contexto social, histórico y cultural en el que se ubican el objeto y sujeto en cuestión? ¿Qué formas toma esa memoria y esas representaciones en el campo social de estudio (objetivación)? ¿Cuál es el peso de las posiciones de los individuos y grupos en la estructura social o de sus relaciones (de igualdad, jerarquía, oposición, etcétera)?

\section{Reflexiones finales}

Para volver a las preguntas iniciales que inspiraron esta reflexión diremos que tanto la TRS como la TMC son de actualidad y pertinencia, debido a que proporcionan las herramientas conceptuales y metodológicas para comprender el pensamiento social contemporáneo y su relación con el pasado. Halbwachs sigue siendo una referencia 
ineludible en los estudios sobre la memoria social, no solo en el campo de las Rs, sino en las ciencias sociales en general.

Retomando la mirada fenomenológica con la que aborda Halbwachs el concepto de memoria colectiva, es claro que la memoria es construida por los individuos que integran grupos y sociedades. Es social porque, como lo postula Durkheim (I895), la sociedad ha otorgado a los individuos las categorías y los esquemas de pensamiento que les permiten percibir $y$ actuar sobre el mundo que los rodea. La sociedad vive en el individuo. Cuando estudiamos las representaciones o la memoria como procesos mentales complejos, tales representaciones o recuerdos estarán anclados en el mundo sociocultural en el que realizamos nuestras investigaciones.

Dado que tanto Halbwachs como Moscovici desarrollan sus constructos teóricos con base en las ideas de Durkheim sobre las representaciones colectivas, podemos suponer que la memoria colectiva es una forma de representación social construida desde el presente por individuos y grupos. Sin embargo, ambos autores se alejan del determinismo sociológico de Durkheim al otorgar, al sujeto que recuerda, cierta autonomía creativa en la construcción de la memoria o de las representaciones. Los sujetos las reelaboran a través de sus experiencias, de sus proyectos, de sus interacciones sociales y formas de comunicación.

La TRS y la MC se erigen como marcos teóricos de amplio alcance, particularmente en el campo de la psicología social latinoamericana. La TRs ha tenido un impacto importante en América Latina a lo largo de las últimas décadas por diversas razones. La primera y más importante es que constituye un referente teórico que aborda los fenómenos psicosociales en su contexto social e histórico. Ello ha permitido a los investigadores latinoamericanos estudiar los procesos sociales y psicológicos que aquejan a nuestras sociedades desde una perspectiva más acorde con la compleja realidad en la que se producen, en contraste con los referentes teóricos propuestos por una psicología social de corte individualista y descontextualizada.

La segunda hace referencia al hecho de que la TRS representó una alternativa ante la crisis teórico-metodológica experimentada por la psicología social desde la década de los sesenta, momento en que se puso en evidencia la limitante que imponía el estudio de los fenómenos psicosociales a partir de microteorías insertas en el marco de la cognición social y del conductismo, así como de herramientas metodológicas que en su afán de control experimental ignoraban la complejidad del fenómeno estudiado.

La tercera tiene que ver con que la TRS permitió recuperar la noción de sujeto como actor social en la medida en que este es considerado como un individuo activo que construye su realidad a partir del contexto sociocultural en el que está inserto. 
Su acción se encuentra en estrecha relación con el sistema de representaciones que le es propio tanto de manera individual como social.

Finalmente, el dinamismo de las representaciones sociales permite integrar una dimensión temporal en el análisis de los procesos psicosociales, lo que concuerda con las rápidas transformaciones de las sociedades contemporáneas y permite estudiarlas tanto en el presente como en el pasado y en el futuro. Por estas razones, y sin duda habrá otras que se me escapan, ${ }^{2}$ la teoría de las Rs ha tenido una buena acogida en los medios académicos latinoamericanos.

Es precisamente por su aspecto dinámico y temporal que las representaciones sociales con concebidas como memorias colectivas cuando el objeto de estudio se mira en el pasado. Varios autores (Nora, 1989; Candeau, 2005) observan un creciente interés por la memoria social o colectiva en las últimas décadas, que puede explicarse por diversas razones:

- Como una necesidad de conocer el pasado para comprender el presente y proyectar el futuro.

- La literatura sobre la modernidad y la posmodernidad sugiere que estas formas de vida producen sociedades amnésicas: la rapidez, la inmediatez del presente y el individualismo que las caracteriza generan nostalgia por la tradición, por reforzar lazos identitarios y un sentimiento de comunidad.

- La reivindicación de la historia, la memoria y la cultura local frente a la supremacía de los procesos económicos y culturales globales por encima de aquellos anclados en territorios nacionales.

- La intención de recuperar el pasado para corregir el presente. La amenaza que representa la alta tecnologización de la agricultura (con la creación de productos genéticamente modificados), la añoranza de la vida campirana frente a la gran urbe, o la pérdida de recursos naturales, se hallan en el centro de las preocupaciones de los movimientos altermundistas y ecologistas para salvar el planeta. El recuerdo imaginario de un medio ambiente más verde impulsa a muchos a querer recuperar los recursos naturales perdidos o a revertir su proceso de destrucción.

- La reivindicación política y de justicia social es uno de los temas más tratados por la literatura sobre la memoria social. Una necesidad de recordar que emerge frente a fenómenos de lucha contra el olvido en caso de guerras, genocidios o sistemas totalitarios. Existe una amplia literatura en América Latina con respecto a los casos de Argentina, Chile y Uruguay, por ejemplo.

2 Jodelet (2000) desarrolla el tema de la contribución de la TRs a la investigación social en América Latina. 
- La abundancia de trabajos sobre la memoria se relaciona tal vez con del desarrollo de una Historial Oral como alternativa de estudio de la memoria social frente a una historia oficial hegemónica.

- El auge del tema podría deberse también al hecho de que existe una multiplicidad de fenómenos sociales relacionados con la identidad y la historia que se ubican bajo el término de "memoria social" de forma genérica (Pereira de Sà, 2005).

A manera de conclusión, me gustaría dar algunas opiniones acerca de la posible continuidad de las investigaciones que articulen las dos teorías puestas en diálogo en este trabajo. Las sociedades inmersas en la era de la información nos plantean nuevos retos en cuanto al avance de los marcos teóricos existentes para estudiar fenómenos sociales emergentes día con día. El futuro de las teorías dependerá entonces de nuestra capacidad como estudiosos de lo social para mantener los ojos abiertos ante los cambios, así como una mente flexible que nos permita comprenderlos y abordarlos. Mantenernos en alerta ante:

- La emergencia de fenómenos nuevos y actores sociales distintos

- Los desafíos teórico-metodológicos que nos impone un mundo altamente tecnologizado en cuanto a la construcción de RS y MC.

- La "visualización" de las Rs y de la MC, en tanto que las imágenes se tornan un elemento indispensable para el análisis del pensamiento social en un mundo dominado por el poder de la imagen visual (Durand, 1996).

- Una realidad virtual cada vez más presente: los intercambios de RS y MC en la web (correos electrónicos, chat, redes sociales, twitter, etc.) altera la rapidez y la forma en que se construyen simbólicamente los eventos del presente y del pasado.

- Adoptar una actitud abierta en el plano teórico y metodológico

- Admitir que los conceptos de representaciones sociales y de memoria colectiva requieren ser relacionados con otras teorías y otras disciplinas para ampliar su capacidad analítica de fenómenos complejos, como los que atañen a las ciencias sociales.

- Flexibilidad metodológica: tradicionalmente, la psicología social ha tenido una fuerte preocupación por la demostración de hipótesis, en el marco del paradigma positivista experimental. La adopción de una postura epistemológica cualitativa, que busque la exploración, descripción y comprensión de los fenómenos de estudio, es necesaria para proporcionar interpretaciones completas de los problemas sociales, insertos en contextos históricos y culturales específicos.

\section{Referencias bibliográficas}


Abric, Jean-Claude (1994), "L'organisation interne des représentations sociales : système central et système périphérique", en Ch. Guimelli, Structures et transformations des représentations sociales, Lausanne, Delachaux Niestlé. Alba, Martha de (2004),"Mapas mentales de la ciudad de México: una aproximación psicosocial al estudio de las representaciones espaciales", Revista de Estudios Demográficos y Urbanos, 19(55).

Alba, Martha de (20I0a), "Sentido de lugar y memoria urbana: Envejecer en el Centro Histórico de la Ciudad de México", Alteridades, 39, pp. 3-8

Alba, Martha de (20Iob), "Representaciones sociales y el estudio del territorio: aportaciones desde el campo de la Psicología Social”, en Salomón González (coord.), La integración de la dimensión espacial en las ciencias sociales y bumanidades: Un proyecto docente interdisciplinario, libro electrónico (http://www.cua.uam.mx/csh/ebook/), México, LAST-UAM-c. Alba, Martha de (2012), "A Methodological Approach to the Study of Urban Memory: Narratives about Mexico City", Forum Qualitative Sozialforschung / Forum: Qualitative Social Research, 13(2), Art. 27, <http:// nbn-resolving.de/urn:nbn:de:OII4-fqsi202276>

Arruda, Angela y Martha de Alba (2007), Espacios imaginarios y representaciones sociales. Aportes desde Latinomérica, España, Anthropos-uam-I.

Banchs, María, Álvaro Agudo y Lislie Astorga (2007), "Imaginarios, representaciones y memoria social", en A. Arruda y M. de Alba (2007), Espacios imaginarios y representaciones sociales. Aportes desde Latinomérica, España, Anthropos-UAM-I.

Candeau, Joel (2005), Anthropologie de la mémoire, París, Armand Colin.

Connexions (2003), Mémoire collective et représentations sociales, 80.

Doise, Willem (1982), L'explication en psychologie sociale, París, PUF.

Doise, Willem (1989), «Cognitions et représentations sociales, l'approche genétique », in D. Jodelet (ed.), Les représentations sociales, París, PUF.

Durand, Gilbert (1996). Introduction a la mythodologie. Mythes et Sociétés. París, Albin Michel.

Durkheim, Emile (1986[1895]), Las reglas del método sociológico, México, Fondo de Cultura Económica.

Durkheim, Emile (1974[1898]), "Représentations individuelles et représentations collectives", Sociologie et philosophie, París, PUF, PP. 13-50 [publicado en Revue de Métaphysique et de Morale, t. VI.].

Durkheim, Emile (20I2[I9I2]), Las formas elementales de la vida religiosa, México, FCE-UAM-UIA. 
Flament, C. (1989), “Structure et dynamique des représentations sociales”, en D. Jodelet (ed.), Les représentations sociales, París, PUF.

Haas, Valerie y Denise Jodelet (1999), “Pensée et mémoire sociale”, en J. Pétard (coord.), Psychologie Sociale, París, Bréal Etidtions.

Halbwachs, Maurice (1994[1925]), Les cadres sociaux de la mémoire, París, Albin Michel.

Halbwachs, Maurice (1997[1950]), La mémoire collective, París, Albin Michel. Jodelet, Denise (1987), "Pensée sociale et historicité", Technologies, idéologies, Pratiques, virI(4).

Jodelet, Denise (1989a), "Représentations sociales : un domaine en expansion”, en Jodelet Denise (ed.), Les représentations sociales, París, PuF.

Jodelet, Denise (1989b), Folies et représentations sociales, París, PUF.

Jodelet, Denise (1992),"Mémoire de masse : le côté moral et affectif de l'histoire", Bulletin de Psychologie, 405, t. XLV, enero-febrero.

Jodelet, Denise (1993), “Mémoires évolutives", en F. Morgiensztern (coord.), Mémoire et intégration, París, Syros.

Jodelet, Denise (2000), "Representaciones sociales: contribución a un saber sociocultural sin fronteras", en Denise Jodelet y Álvaro Guerrero, Develando la cultura. Estudios en Representaciones Sociales, México,unam.

Jodelet, Denise (2010), "La memoria de los lugares urbanos", Alteridades 39(20), pp. 77-85.

Jodelet, Denise (2012), "Conflits entre histoire memorielle et histoire historienne", Psicologia e Saber Social, I(2), pp. I5I-162.

Laurens, S. y N. Roussiau (eds.) (2002), La mémoire sociale. Identités et représentations sociales, Rennes, PUR.

Le Paumier, Frédéric y Marisa Zavalloni (2002)"Mémoire collective et système identitaire : de Maurice Halbwachs à l'ego-écologie », en S. Laurens y N. Roussiau (eds.), La mémoire sociale. Identités et représentations sociales. Rennes, PUR.

Marková, Ivana (200I), "Social representations and communicative genres" en F. Buschini y N. Kalampalikis, N. (dir.), Penser la vie, le social, la nature. Mélanges en l'honneur de Serge Moscovici, París, Éditions de la Maison des sciences de l'homme, pp. 219-235.

Milgram, Stanley y Denise Jodelet (1976), "Psychological maps of Paris", en Proshansky, Ittelson, Rivlin (eds.) Environmental psychology: people and their physical settings, Nueva York, Holt Rinehart and Winston

Moscovici, Serge (196I), La psychanalyse, son image et son public, París, PUF. 
Moscovici, Serge(1976), Psicología de las minorías activas, Barcelona, Paidós. Moscovici, Serge(1989), "Des représentations collectives aux représentations sociales", en Denise Jodelet (ed.), Les représentations sociales, París, PUF.

Moscovici, Serge e I. Marková (1998), "Presenting Social Representations: a conversation", Culture and Psychology, 4(3), pp. 371-410.

Nora, Pierre (1989),"Between memory and history: les lieux de Memoire", Representations, 26, pp. 7-24.

Pereira de Sá, Celso (2005), Imaginário e Representçoes Sociais, Río de Janeiro, Museo da República.

Pereira de Sá, Celso y D. Oliveira (2002),"Sur la mémoire sociale de le découverte du Brésil", en Stéphane Laurens y Nicolas Roussiau (eds.), La mémoire sociale. Identités et représentations sociales, Rennes, PUR.

Ricoeur, Paul (2000), La mémoire, l'histoire, l'oubli, París, Editions du Seuil.

Rosa Ribero, Alberto et al. (2000), Memoria colectiva e identidad nacional, Madrid, Biblioteca Nueva.

Rosa Ribero, Alberto (2005), "El impacto social de las imágenes y el reparto social de las emociones en la construcción de la memoria social: una impactante memoria flash de masa del in de septiembre ante la guerra de Iraq", en Celso Pereira de Sà (ed.), Imaginário e Representçoes Sociais, Río de Janeiro, Museo da República. 